\title{
In Vivo Real-Time Imaging of TGF- $\beta$-Induced Transcriptional Activation of the RANK Ligand Gene Promoter in Intraosseous Prostate Cancer
}

\author{
Jian Zhang, ${ }^{1} \mathrm{Yi} \mathrm{Lu}^{2}{ }^{2}$ Jinlu Dai, ${ }^{1}$ Zhi Yao, ${ }^{2}$ Riko Kitazawa, ${ }^{3}$ Sohei Kitazawa, ${ }^{3}$ \\ Xinping Zhao, ${ }^{4}$ Daniel E. Hall, ${ }^{5}$ Kenneth J. Pienta, ${ }^{6}$ and Evan T. Keller ${ }^{1 *}$ \\ 'Department of Pathology and Unit for Laboratory Animal Medicine, School of Medicine, \\ University of Michigan, Ann Arbor, Michigan \\ ${ }^{2}$ Department of Immunology, Tianjin Medical University, Tianjin, China \\ ${ }^{3}$ Division of Molecular Pathology, Kobe University, Kobe, Japan \\ ${ }^{4}$ Department of Neurology, School of Medicine, University of Michigan, Ann Arbor, Michigan \\ ${ }^{5}$ Center for Molecular Imaging, School of Medicine, University of Michigan, Ann Arbor, Michigan \\ ${ }^{6}$ Department of Medicine and Urology, School of Medicine, University of Michigan, Ann Arbor, Michigan
}

\begin{abstract}
BACKGROUND. Current animal models of prostate cancer (CaP) bone metastasis do not allow measurement of either tumor growth in bone over time or activation of gene promoters in intraosseous tumors. To develop these methods, we used bioluminescent imaging (BLI) to determine if expression of receptor activator of NF- $\kappa \mathrm{B}$ ligand (RANKL), a pro-osteoclastogenic factor that promotes $\mathrm{CaP}$ bone metastases, is modulated by the bone matrix protein transforming growth factor- $\beta$ (TGF- $\beta$ ) in vivo.

METHODS. C4-2B human CaP cells were treated with TGF- $\beta$ in vitro and RANKL mRNA and protein production were measured by polymerase chain reaction (PCR) and ELISA, respectively. Then $\mathrm{C} 4-2 \mathrm{~B}$ cells stably transfected with the RANKL promoter driving luciferase (lux) were injected intra-tibially into severe combined immundeficient (SCID) mice. Tumors were subjected to BLI every 2 weeks for 6 weeks and serum prostate specific antigen (PSA) was measured using ELISA. Vehicle (V), 1,25 dihydroxyvitamin D (VitD), or TGF- $\beta$ was administered to mice with established tumors and BLI to measure RANKL promoter activity was performed. Tumors were then subjected to immunohistochemistry for lux and assayed for RANKL mRNA levels.

RESULTS. TGF- $\beta$ induced RANKL protein and mRNA expression and activated the RANKL promoter activity in a dose-dependent manner in vitro. BLI demonstrated an increase in intraosseous tumor size over time, which correlated with serum PSA levels. Administration of TGF- $\beta$ and VitD to mice with established intraosseous tumors increased lux activity compared
\end{abstract}

\begin{abstract}
Abbreviations: ANOVA, analysis of variance; BLI, bioluminescent imaging; $\mathrm{CaP}$, prostate cancer; DMEM, Dulbecco's minimum essential medium; ECM, extracellular matrix; FBS, fetal bovine serum; GAPDH, glyceraledhyde-3-phosphate dehydrogenase; HRP, horseradish peroxidase; OPG, osteoprotegerin; PAGE, polyacrylamide gel electrophoresis; PBS, phosphate-buffered saline; PCR, polymerase chain reaction; PMSF, phenylmethylsulfonyl fluoride; PSA, prostatespecific antigen; $\mathrm{PTH}$, parathyroid hormone; $\mathrm{PTHrP}$, parathyroid hormone-related protein; RANK, receptor activator of NF- $\mathrm{kB}$; RANKL, receptor activator of NF- $\mathrm{KB}$ ligand; RT-PCR, reverse transcriptionpolymerase chain reaction; SCID, severe combined immundeficient; SDS, sodium dodecyl sulfate; TGF- $\beta$, transforming growth factor- $\beta$; $\mathrm{TNF}$, tumor necrosis factor; VitD, 1,25-dihydroxyvitamin D.
\end{abstract}

Grant sponsor: USAMRMC Prostate Cancer Research Program; Grant number: DAMD17-03-1-0092; Grant sponsor: National Cancer Institute; Grant number: SPORE 1 P50 CA69568; Grant sponsor: University of Michigan's Cancer Center; Grant number: 5 P30 CA46592 and Grant number P01 CA093900

*Correspondence to: Evan T. Keller, DVM, PhD, Unit for Laboratory Animal Medicine, and Department of Pathology, University of Michigan School of Medicine, 1500 E. Medical Ctr. Dr., Ann Arbor, MI 48109-0940. E-mail: etkeller@umich.edu

Received 27 June 2003; Accepted 21 October 2003

DOI 10.1002/pros.20019

Published online 23 December 2003 in Wiley InterScience (www.interscience.wiley.com). 
to V. Intratibial tumor RANKL mRNA expression paralleled the increased promoter activity. Immunohistochemistry confirmed the presence of lux in the intraosseous tumors.

CONCLUSIONS. These results demonstrate the ability to measure intraosseous tumor growth over time and gene promoter activation in an established intraosseous tumor in vivo and also demonstrate that TGF- $\beta$ induces activates the RANKL promoter. These results provide a novel method to explore the biology of CaP bone metastases. Prostate 59: 360-369, 2004.

(c) 2003 Wiley-Liss, Inc.

\section{KEY WORDS: TGF- $\beta$; RANKL transcription; bioluminescent imaging; prostate cancer;} bone metastasis

\section{INTRODUCTION}

Prostate cancer $(\mathrm{CaP})$ has a great predisposition to metastasizing to bone where it forms mixture of osteolytic and osteoblastic lesions (reviewed in Refs. 1,2). The importance of the osteolytic component to the development of $\mathrm{CaP}$ bone metastases has been demonstrated by both histological examination of clinical metastases and several in vivo studies [3-6]. CaPinduced bone resorption is primarily caused by osteoclasts [7]. Receptor activator of NF- $\kappa B$ ligand (RANKL), a tumor necrosis factor (TNF) family member, plays an essential role for induction of osteoclastogenesis through binding and activating RANK on osteoclast precursors [8]. Osteoprotegerin (OPG) is a soluble decoy receptor for RANKL and blocks the binding of RANKL to RANK resulting in inhibition of osteoclastogenesis [9]. RANKL expression is increased in $\mathrm{CaP}$ cells at bone metastatic sites of $\mathrm{CaP}$ patients [10] and in some but not all $\mathrm{CaP}$ cell lines [5,11]. In addition, $\mathrm{CaP}$-induced osteoclast activity is mediated through RANKL and can be inhibited by administration of OPG [5,6]. Thus, understanding the regulation of RANKL in CaP cells may help design therapies to inhibit $\mathrm{CaP}$ bone metastases.

RANKL is expressed in a variety of cells including bone-derived endothelial cells, human umbilical vein endothelial cells, T lymphocytes, osteoblasts, and bone marrow stromal cells [12]. However, there are limited published data regarding the regulation of RANKL expression. It has been reported that activation of T cells $[13,14]$, parathyroid hormone [15,16], 1,25-dihydroxyvitaminD (VitD) [17], and inflammatory cytokines $[18,19]$ upregulate RANKL expression and that vitamin K downregulates RANKL expression [20]. However, the mechanism of how RANKL expression is regulated by these factors has not been reported.

The bone extracellular matrix $(E C M)$ is rich in a variety of growth factors that may influence RANKL expression. For example, transforming growth factor- $\beta$ (TGF- $\beta$ ), which is abundantly stored in bone ECM, promotes osteoclastogenesis [21]. TGF- $\beta$ is released from the bone ECM during cancer-induced bone resorption [22]. Although TGF- $\beta$ is release during bone resorption and may influence $\mathrm{CaP}$ progression in bone, its ability to modulate RANKL expression in $\mathrm{CaP}$ cells is currently unknown.

Evaluating regulation of gene expression at the gene promoter level is typically done in vitro with promoter-driven reporter assays or nuclear run on assays. These assays are typically insensitive and complicated, respectively, and do not necessarily reflect regulation of the gene in the endogenous environment. Due to these limitations, improved methods to identify gene promoter activation in vivo would enhance investigators' ability to explore gene regulation. In this study, we tested if TGF- $\beta$ induces RANKL expression at the promoter level in established intraosseous $\mathrm{CaP}$ tumors in vivo using a novel method to identify activation of the promoter in vivo.

\section{MATERIALS AND METHODS}

\section{Reagents}

For in vitro experiments, 1,25-dihydroxyvitamin D3 (VitD3) Sigma-Aldrich, Inc., (St. Louis, MO) was diluted to $10^{-3} \mathrm{M}$ stock solution in ethanol, then diluted further in phosphate-buffered saline (PBS) as required. For in vivo experiments, VitD3 was diluted in propylene glycol. TGF- $\beta$ (R\&DSystems, Minneapolis, MN) was diluted as required into PBS.

\section{Animals}

Six-week-old male severe combined immunodeficient (SCID) mice (Charles River, Wilmington, MA) were housed under pathogen-free conditions. An animal protocol for this study was approved by the University of Michigan Animal Care and Use Committee.

\section{Cells}

The human prostate C4-2B cells (UroCor, Inc., Oklahoma City, OK) are derived from LNCaP cells through several passages via castrated nude mice and isolated from the tumor that metastasize to bone [23]. The C4-2B cells were maintained in T medium $(80 \%$ Dulbecco's minimum essential medium (DMEM, Life Technologies, Inc., Grand Island, NY), 20\% F12K (Irving Scientific, Santa Ana, CA), 3 g/L $\mathrm{NaHCO}_{3}$, 
$100 \mathrm{U} / \mathrm{L}$ penicillin $\mathrm{G}, 100 \mu \mathrm{g} / \mathrm{ml}$ streptomycin, $5 \mu \mathrm{g} / \mathrm{ml}$ insulin, $13.6 \mathrm{pg} / \mathrm{ml}$ triiodothyronine, $5 \mu \mathrm{g} / \mathrm{ml}$ apotransferrin, $0.25 \mu \mathrm{g} / \mathrm{ml}$ biotin, $25 \mu \mathrm{g} / \mathrm{ml}$ adenine) that was supplemented with $10 \%$ fetal bovine serum (FBS). DU-145 and PC-3 CaP cells (American Type Culture Collection, Manassas, VA) were maintained in RPMI media supplemented with $10 \%$ FBS.

\section{RANKL Promoter Cloning}

A total of $1 \times 10^{6}$ recombinants from the human genomic library (Clontech) were screened by plaque hybridization using a probe consisting of polymerase chain reaction (PCR)-amplified exon 1 of the human RANKL gene as previously published [24]. A 1,974 bp clone (Genbank AF544022) was isolated. Primer extension using a poly $(\mathrm{T})+$ oligo positioned the major transcriptional initiation site 157 nucleotides upstream from the initial methionine site, and this was assigned the +1 position. The $5^{\prime}$-flanking sequence around the transcription initiation site of the human RANKL gene contained TATA- and CAAT-boxes at -22 and $-56 \mathrm{bp}$.

Sac I and Hind III adaptors were ligated onto the $5^{\prime}$ - and $3^{\prime}$-ends, respectively, of the promoter. The pGL3-Basic vector (Promega, Madison, WI) was digested with Sac I and Hind III and the modified promoter fragment was directionally ligated into the plasmid upstream of the luciferase (lux) coding sequence. Both strands were sequenced by the dideoxy nucleotide termination method with an ABI PRISM 310 automated sequence analyzer (Applied Biosystems) to confirm the cloning process.

\section{StableTransfection}

C4-2B $\left(5 \times 10^{5}\right)$ cells plated in $60 \mathrm{~mm}$ dishes then were stably co-transfected with RANKL promoter driving lux plasmid $(1 \mu \mathrm{g})$ or empty PGL-3-basic vector as control $(1 \mu \mathrm{g})$ with an expression vector for neomycin resistance (pcDNA3.1+) $(0.1 \mu \mathrm{g})$ with the use of SuperFect reagent (Qiagen, Valencia, CA) according to the manufacturer's instructions. Selection for the neomycin resistance was initiated $48 \mathrm{hr}$ after transfection by adding $600 \mu \mathrm{g} / \mathrm{ml}$ of G418 (Life Technologies, Inc.) to the culture medium. The selection medium was changed every 4 days for 5 weeks. Surviving G418resistant cells were pooled and tested for lux expression. Lux expression was stably maintained after ten passages in the absence of G418.

\section{Tumor Cell Inoculation}

For intratibial injection tumors, single-cell suspensions $\left(3 \times 10^{5}\right.$ cells) of $\mathrm{C} 4-2 \mathrm{~B}$ cells in $\mathrm{T}$ media were injected into the right tibia of the male SCID mice ( $\mathrm{n}=8$ per group) as described previously [5]. Briefly, mice were anesthetized (135 mg ketamine, $15 \mathrm{mg}$ xylazine $/ \mathrm{kg}$ body weight), the knee was flexed, and a $26 \mathrm{~g}, 3 / 8$-inch needle was inserted into the proximal end of right tibia followed by injection of $20 \mu \mathrm{l}$ of the cell suspension.

For subcutaneous tumor development, C4-2B cells were resuspended in T-media plus 10\% FBS and cells $\left(1 \times 10^{6}\right)$ were then injected in the flank at $100 \mu \mathrm{l} /$ site using a $23 \mathrm{G}$ needle. Subcutaneous tumor growth was identified by palpation and two perpendicular axes were measured and the tumor volume was calculated using the formula: volume $=$ length $\times \operatorname{width}^{2} / 2$, as previously described [5].

\section{Radiographic Analysis}

Magnified flat radiographs were taken with a Faxitron (Faxitron X-Ray Corp., Wheeling, IL).

\section{Luciferase Measurement}

In some instances, as indicated in the figure legends, in vitro lux production was measured using a luminometer (Lumat LB9501, Berthold). In other instances, in vitro and in vivo bioluminescence imaging were performed on a cryogenically cooled imaging system (Xenogen Corporation, Alameda, CA) coupled to a data acquisition computer. The stable transfectant used in vivo study was first tested in vitro by adding $20-\mu \mathrm{l}$ luciferin $(40 \mathrm{mg} / \mathrm{ml})$ into the 96 -wells plate. Luminescence emitted from the plate was integrated for $1 \mathrm{~min}$ starting immediately after adding luciferin. For the in vivo study, prior to imaging, animals were anesthetized in an acrylic chamber with $1.5 \%$ isofluorane/air mixture and injected through intraperitoneal with $40 \mathrm{mg} / \mathrm{ml}$ of luciferin potassium salt in PBS at a dose of $150 \mathrm{mg} / \mathrm{kg}$ body weight as previously described [25] A digital gray scale animal image was acquired followed by acquisition and overlay of a pseudocolor image representing the spatial distribution of detected photon counts emerging from active lux within the animal. Photon counts emitted from the mouse were collected for $1 \mathrm{~min}$ starting $10 \mathrm{~min}$ after injection of luciferin. Images were processed and photon counts were quantified using Living Image software (Xenogen Corporation).

\section{Histopathology and Immunohistochemistry}

Histopathology was performed as we have previously described [5]. Briefly, bone specimens were fixed in $10 \%$ formalin for $24 \mathrm{hr}$, then decalcified using $12 \%$ EDTA for $72 \mathrm{hr}$. The specimens were then paraffin embedded, sectioned $(5 \mu \mathrm{M})$ and stained with hematoxylin and eosin (H\&E) to assess histology.

Non-stained tissues sections were deparaffinized and rehydrated then stained for lux with mouse anti- 
lux monoclonal antibody (Sigma) and biotinylated anti-mouse IgG antibody for detection using peroxidase staining as recommended by the manufacturer (mouse ABC Staining Systems; Santa Cruz Biotechnology, Santa Cruz, CA).

\section{Western Blot Analysis}

To evaluate the effect of TGF- $\beta$ on RANKL protein expression in C4-2B cells $\left(2 \times 10^{6}\right)$ were plated in T75 flasks and treated with different dose of TGF- $\beta$, vehicle $(\mathrm{V})$, or VitD for $24 \mathrm{hr}$ and the cells washed twice with PBS and then lysed in RIPA buffer (1× PBS, $1 \%$ Nonidet $\mathrm{P}-40,0.5 \%$ sodium deoxycholate, $0.1 \%$ sodium dodecyl sulfate (SDS)) with $100 \mathrm{ng} / \mathrm{ml}$ PMSF. proteins (40 $\mu \mathrm{g} /$ lane) from the cell lysates were applied to SDSpolyacrylamide gel electrophoresis (PAGE) followed by Western blot analysis with mouse anti-human RANKL monoclonal antibody (R\&D Systems). The antibody binding was revealed using a horseradish peroxidase (HRP)-conjugated anti-mouse IgG (Amersham Pharmacia Biotech, Piscataway, NJ) and enhanced chemiluminescence (ECL) blot detection system (Amersham Pharmacia Biotech).

\section{Real-Time PCR}

To isolate total mRNA from tumors within the mouse tibia, individual tibiae were excised from the mice and the distal $1 \mathrm{~cm}$ of the tibia was isolated using bone cutters, then ground using a steel bone mill (BioComp MiniMill, Biomedical Composites, Ltd., Ventura, CA) in $1 \mathrm{ml}$ of RNase-free PBS. The ground substance was vortexed for $1 \mathrm{~min}$, the chips allowed to settle and the supernatant was aspirated and the pellet was mixed with $1 \mathrm{ml}$ of Trizol reagent (Life Technologies, Inc.), vortexed for $30 \mathrm{sec}$, then homogenized for three $10 \mathrm{sec}$ intervals and centrifuged at $10,000 \mathrm{rpm}$ for $30 \mathrm{sec}$. The supernatant is collected and subjected to total RNA isolation as described by the manufacturer. To isolate total mRNA from C4-2B cells in vitro, Trizol Reagent (Life Sciences) was added to the plates as described by the manufacturer. Total RNA (200 ng) was subjected to real-time reverse transcription-PCR (RT-PCR) using a LightCycler SYBR Green I RNA amplification kit according to the manufacturer's instructions (Roche Diagnostics, Indianapolis, IN). RT-PCR reactions were subjected to 45 cycles of $94^{\circ} \mathrm{C}$ for $5 \mathrm{sec}, 55^{\circ} \mathrm{C}$ for $10 \mathrm{sec}$, and $72^{\circ} \mathrm{C}$ for $1 \mathrm{~min}$. RT-PCR of glyceraledhyde-3-phosphate dehydrogenase (GAPDH) transcripts was used as an internal control to normalize for loading differences between samples. PCR primers used for detection of RANKL mRNA consisted of upstream: 5'-GCTTGAAGCTCAGCCTTTTGCTCAT-3' and downstream: 5'-GGGGTTGGAGACCTCGATGCTGATT-3'. PCR primers used for detection of GAPDH
mRNA consisted of upstream: 5'-GGAGTCAACGGATTTGGT-3' and downstream: 5'-GTGATGGGATTTCCATTGAT-3'.

\section{Prostate Specific Antigen (PSA) Measurement}

Blood was collected via tail vein every 2 weeks during the study and serum was harvested and frozen at $-80^{\circ} \mathrm{C}$ until assayed. Total PSA levels in serum were determined using the Accucyte Human PSA assay (Cytimmune Sciences, Inc., College Park, MA). The sensitivity of this assay is $0.488 \mathrm{ng} / \mathrm{ml}$.

\section{Statistical Analysis}

Statistical analysis of the data was performed using Statview Software (Abacus Concepts, Berkley, CA). Analysis of variance (ANOVA) was used for initial analysis followed by Fisher's protected least significance for post-hoc analyses. Differences were considered to be significantly significant when a $P$-value $<0.05$ was found. To compare the relation between PSA and tumor volume, simple linear regression was used.

\section{RESULTS}

To determine if TGF- $\beta$ induces RANKL expression in C4-2B CaP cells in vitro. C4-2B cells were incubated with increasing doses of TGF- $\beta$ then RANKL protein in the culture media and cellular RANKL mRNA expression was measured. Additionally, VitD, a known inducer of RANKL expression [26], was used as a positive control. TGF- $\beta$ induced RANKL protein expression in dose-responsive fashion with approximately a fourfold induction at $10 \mathrm{ng} / \mathrm{ml}$ of TGF- $\beta$ (Fig. 1). Similarly, TGF- $\beta$ induced RANKL mRNA expression in dose-responsive fashion with approximately a sevenfold induction at $10 \mathrm{ng} / \mathrm{ml}$ of TGF- $\beta$ (Fig. 1). These data indicate that TGF- $\beta$ can induce RANKL protein through increasing RANKL mRNA steady state levels. Increased steady state levels may be due to either increased transcriptional activation and/or decreased mRNA degradation. To determine if activation of the RANKL promoter could contribute to the increased RANKL mRNA expression, we stably transfected C4-2B cells with a lux reporter vector driven by the human RANKL promoter then treated the stably transfected cells with TGF- $\beta$. RANKL promoter activity, as indicated by lux levels, was then measured using luminescent imaging. TGF- $\beta$ induced RANKL in a dose-responsive fashion with approximately a 3.7-fold induction at $10 \mathrm{ng} / \mathrm{ml}$ of TGF- $\beta$ (Fig. 2). VitD also induced the RANKL promoter as expected. Taken together, these data demonstrate that TGF- $\beta$ increases RANKL expression, in part, through activation of the RANKL promoter. 

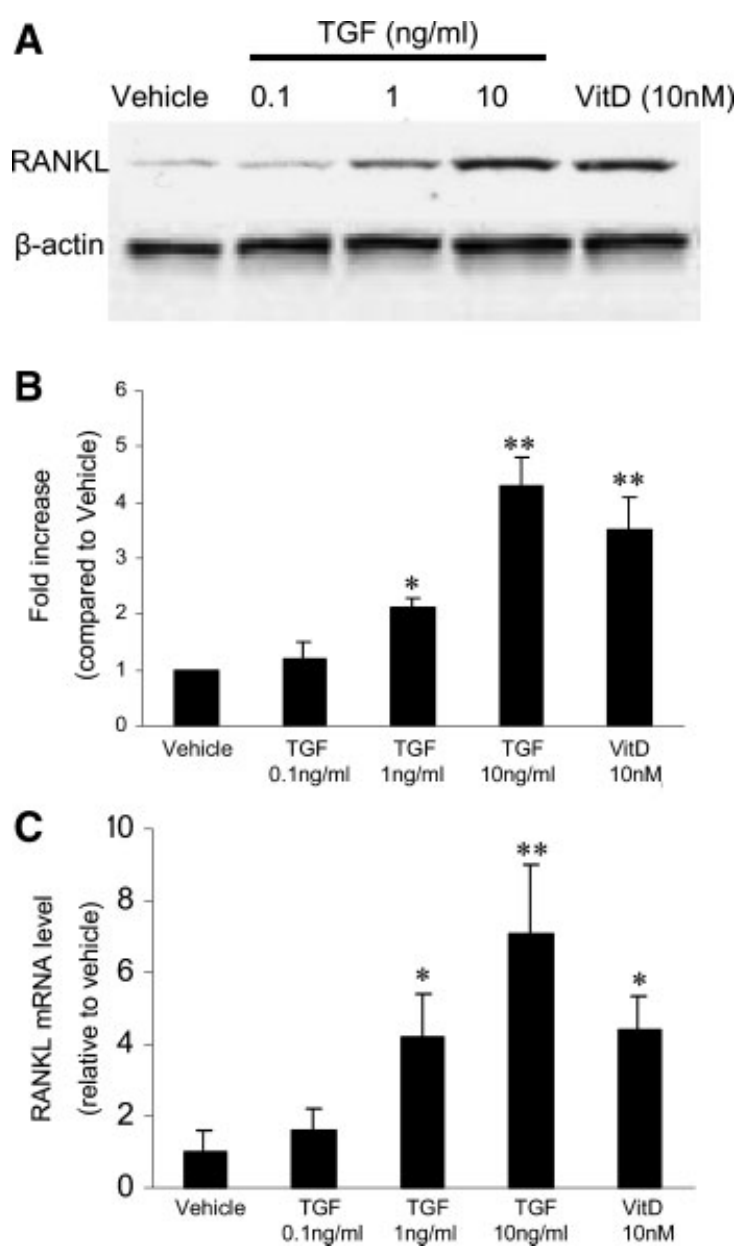

Fig. I. Transforming growth factor- $\beta$ (TGF- $\beta$ ) induces RANKL protein and mRNA expression in C4-2B cells. A: C4-2B cells were treated with vehicle (V), TGF- $\beta$, or I,25-dihydroxy vitamin D(VitD3) for $24 \mathrm{hr}$ at the indicated doses. Total cellular protein from C4-2B cells was subjected to Western blot analysis for RANKL. Then the membrane was stripped and reprobed for $\beta$-actin. B: RANKL protein band density was quantified using densitometric analysis. RANKL bands were normalized to $\beta$-actin bands. Results are reported as mean $\pm S D$ from three independent experiments. $* P<0.0$ l, $* * P<0.00$ l as compared with vehicle-treated cells. $\mathbf{C}$ : Total RNA was isolated from C4-2B cells treated as indicated. RANKL mRNA expression was evaluated by real-time PCR. Human glyceraledhyde-3-phosphate dehydrogenase (GAPDH) mRNA was used to normalize between samples. Results are reported as mean $\pm S D$ from three independent experiments, each one performed with triplicates measurements of PCR products. $* P<0.0$ l, ${ }^{* *} P<0.001$ as compared with vehicle treated cells.

To better recapitulate the RANKL promoter response in $\mathrm{CaP}$ bone metastases, the response of the RANKL promoter to TGF- $\beta$ in vivo in $\mathrm{C} 4-2 \mathrm{~B} \mathrm{CaP}$ tumors established in bone was evaluated. Accordingly, we injected C4-2B cells stably-transfected with the RANKL-lux reporter vector into the tibia of mice and tumor was allowed to grow over 6 weeks. To identify development of tumors, radiographs of the
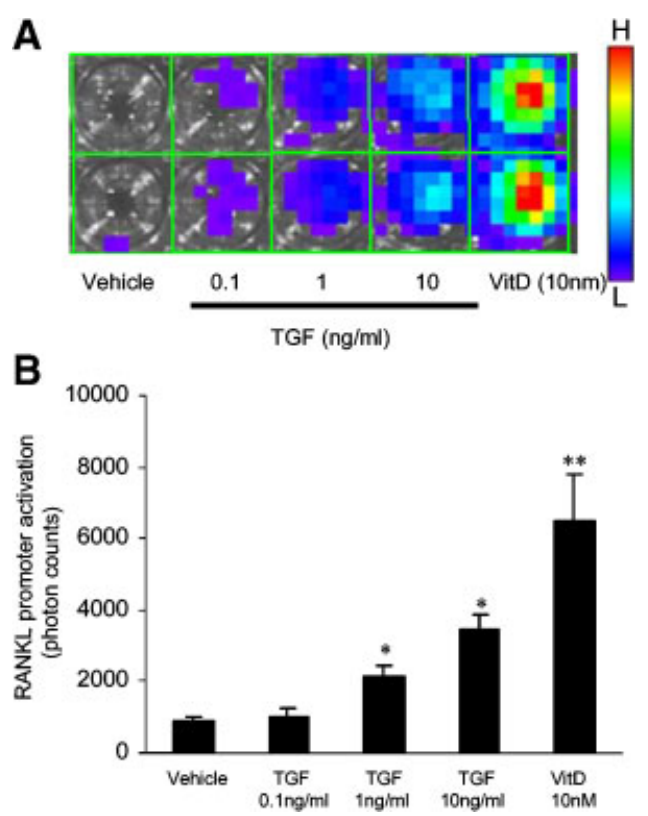

Fig. 2. TGF- $\beta$ induces RANKLtranscription in $C 4-2 B$ cells invitro. A: C4-2B cells were stably transfected with human RANKL promoter ( $1.97 \mathrm{~kb}$ ) driving luciferase (lux). The stably transfected C4-2B cloneswerepooledand platedin 96 -well-platesand treated withvehicle (V), TGF- $\beta$, or I,25-dihydroxy vitamin D (VitD3) for $24 \mathrm{hr}$ at indicated doses. Luciferin was added to each well and imaging was performed using IVIS ${ }^{\mathrm{TM}}$ Xenogen Imaging system (Xenogen Corporation, Alameda,CA). Photoncounts were collectedover a minute period. A duplicate sample is shown. The scale bar indicates luminescence intensity from high $(\mathrm{H})$ tolow $(\mathrm{L})$. B: Photon counts were quantified. Results are reported as the mean \pm SD from duplicates measurements of pooled clones. $* P<0.0$ l, $* * P<0.001$ compared with vehicle. [Color figure can be viewed in the online issue, which is available at www.interscience. wiley.com.]

tibia were taken every 2 weeks after tumor injection up to 6 weeks. Radiographic changes were not identified until 6 weeks after tumor injection (Fig. 3A). They consisted of mixed osteolytic and osteoblastic changes as previously reported for $\mathrm{C} 4-2 \mathrm{~B}$ cells in bone. In contrast, tumor was identifiable as early as 2 weeks using bioluminescent imaging (BLI) and increasing tumor growth in bone was detectable over time using BLI of living mice (Fig. 3B,C). To ensure that the increased BLI reflected tumor burden, serum PSA was measured. The mouse does not make PSA, thus the serum PSA confirms the C4-2B tumor burden in the mice. PSA levels increased over time in a similar fashion to the lux levels (Fig. 3D). The BLI of the tumors was strongly correlated with PSA levels (Fig. 3E). These data indicate that BLI can be used to non-invasively measure tumor growth in bone over time in mice.

Once tumors were developed, VitD (as positive control) and TGF- $\beta$ were administered to the mice. Both VitD and TGF- $\beta$ transiently induced RANKL promoter activity in the C4-2B cells in bone (Fig. 4A,B). 


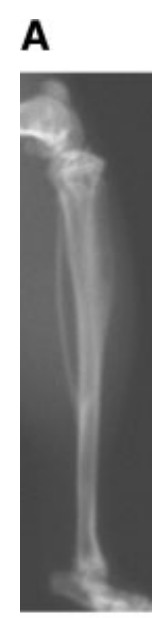

0

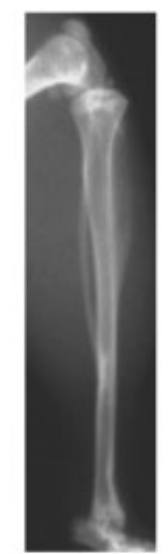

2 Time (weeks post-tumor injection)

D
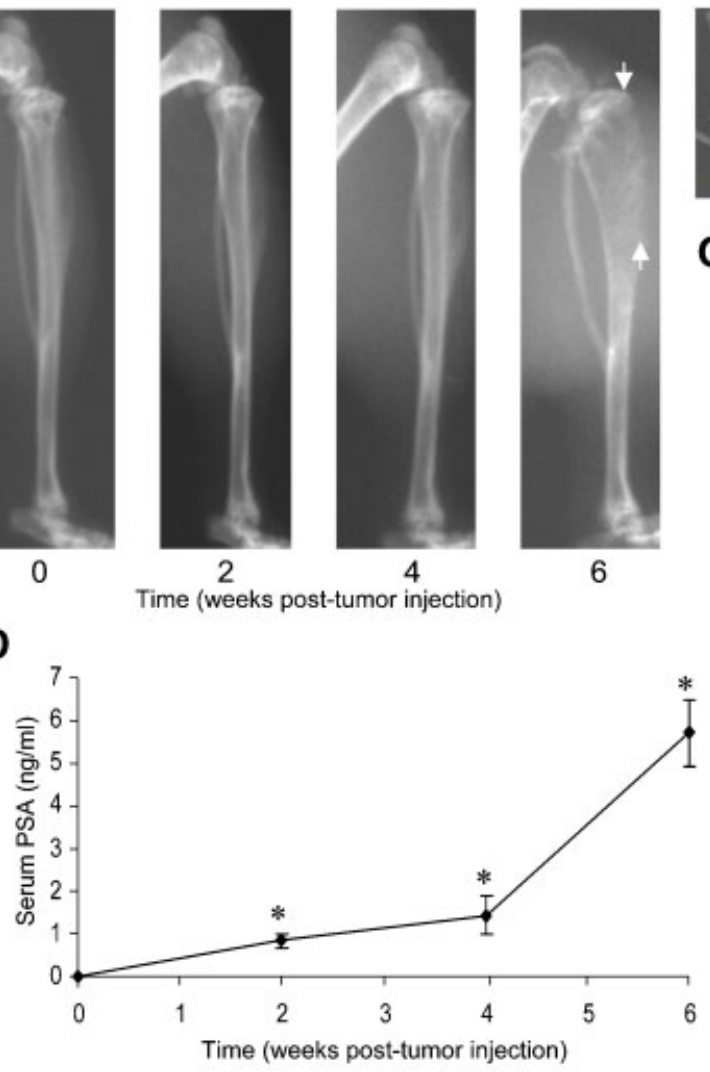

6
B
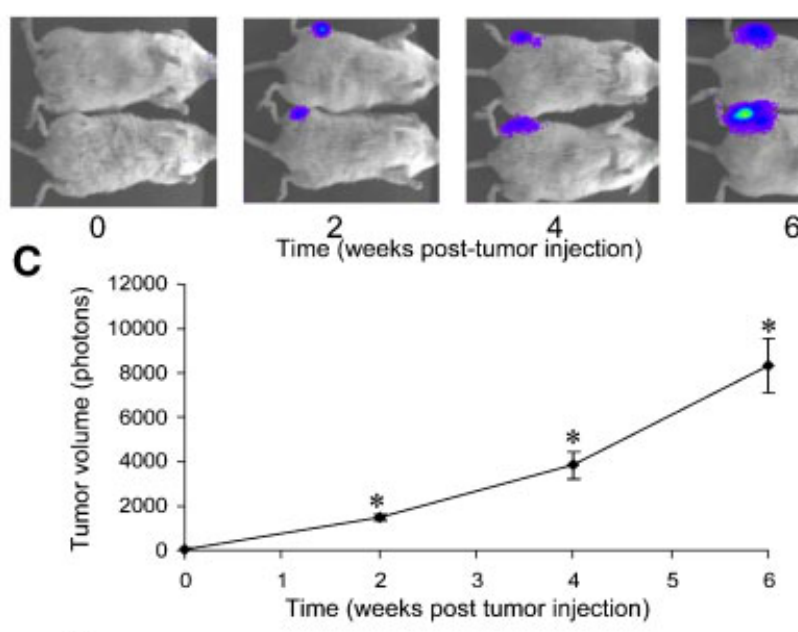

E

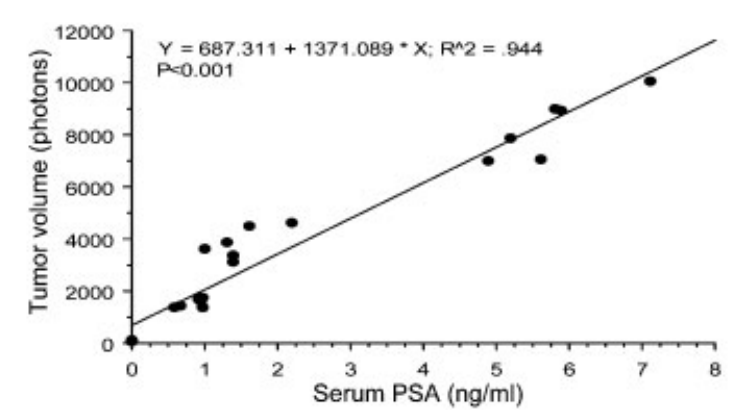

Fig. 3. Bioluminescent imaging (BLI) can be used to detect tumor growth in bone in vivo over time. C4-2B prostate cancer (CaP) cells were stably transfected with a reporter vector of the RANKL promoter driving lux. The transfected C4-2B cells were injected intratibially into severe combined immundeficient (SCID) mice $(n=6)$. Mice were subjected to radiographs and BLI for lux every 2 weeks post-tumor injection at which time serum was collected and frozen for prostate specific antigen (PSA) evaluation. A: Radiographs of a mouse tibia injected with $\mathrm{C} 4-2 \mathrm{~B}$ CaP cells. Tumor-induced changes are noted between the arrowheads. B: Representative scan of two mice demonstrating luminescence in the tibia. Lower mouse is the same as in $(A)$. The scale bar indicates luminescence intensity from high $(H)$ to low $(L)$. C: Quantification of luminescence from six animals. Photon counts were collected over a minute period. Results are reported as the mean $\pm S D$. $* P<0.01$ compared to the measurement 2 weeks prior. D: Serum PSA levels were determined using ELISA. Results are reported as the mean \pm SD. $* P<0.0$ I compared to the measurement 2 weeks prior. E: Regression analysis between BLI-measured tumor volume and serum PSA. [Color figure can be viewed in the online issue, which is available at www.interscience. wiley.com.]

To determine if the observed pattern of RANKL promoter activity in vivo was due to pharmacokinetics of VitD or TGF- $\beta$, we exposed cells in vitro to these compounds and measured lux expression. The transient nature of the RANKL promoter induction was repeated in vitro (Fig. 4C) indicating this was not a pharmacokinetic effect. To confirm that VitD and TGF$\beta$-induced promoter activity was associated with increased RANKL production in vivo, we measured RANKL mRNA levels in the bone tumors. Both VitD and TGF- $\beta$ induced RANKL mRNA expression (Fig. 4D). Histology of the tumors was performed and confirmed the presence of tumor in bone (Fig. 4E). Furthermore, to confirm that the tumors were making lux, we performed immunohistochemistry for lux on the tumor sections. Lux was colocalized within the tumor cells in bone (Fig. 4E), which confirms that the C4-2B cells were expressing lux in the tumor site and that the RANKL promoter was active at this site. Taken together, these results demonstrate that TGF- $\beta$ induces the RANKL promoter in bone and that BLI imaging can be utilized to measure promoter activation within tumors in vivo.

\section{DISCUSSION}

In the current study, we demonstrated both the ability to quantify activation of a gene promoter in intraosseous $\mathrm{CaP}$ as well as quantify intraosseous $\mathrm{CaP}$ tumor growth over time. In addition to these methodological advances, we identified that TGF- $\beta$, a protein found at high levels in the bone ECM, promotes $\mathrm{CaP}$ mediated RANKL production through activation, in part, of the RANKL promoter. Taken together, these results contribute to both the understanding of how 
bone crosstalks with $\mathrm{CaP}$, as well as providing new methodologies to explore bone and CaP crosstalk.

Evaluating promoter activity in vitro is fraught with inconsistencies. For example, the substrate of the cell culture plates can influence signaling in the cells, monolayer cultures do not recapitulate the three dimensional context of tumor structures, which can influence cell's response to compounds or compounds administered in vitro may be metabolized to another active (or inactive) compound in vivo. Thus, observations from in vitro promoter studies may not reflect the in vivo modulation of the promoter.

Determining gene promoter regulation in vivo is quite challenging. Recent advances in BLI have allowed for the ability to identify activation of gene promoters in mice genetically modified to express lux driven by either a constitutive or inducible promoter [27]. However, evaluation of promoter activation
A

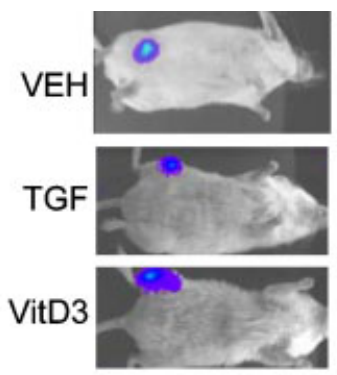

Pre-TX

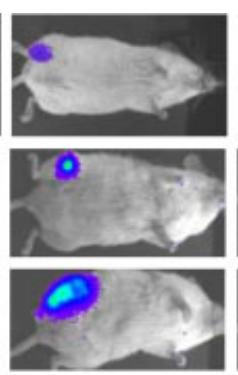

$1 \mathrm{hr}$

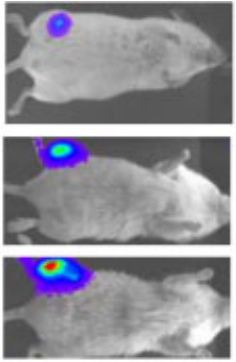

$6 \mathrm{hr}$

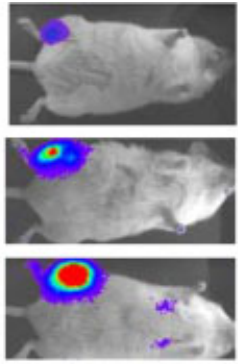

$12 \mathrm{hr}$

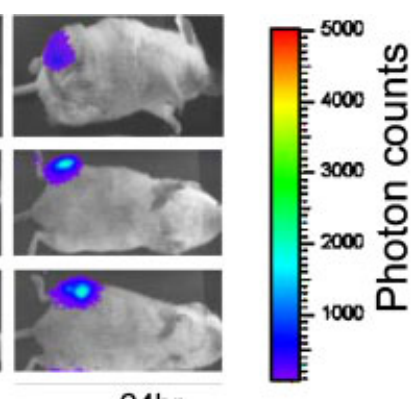

$24 \mathrm{hr}$

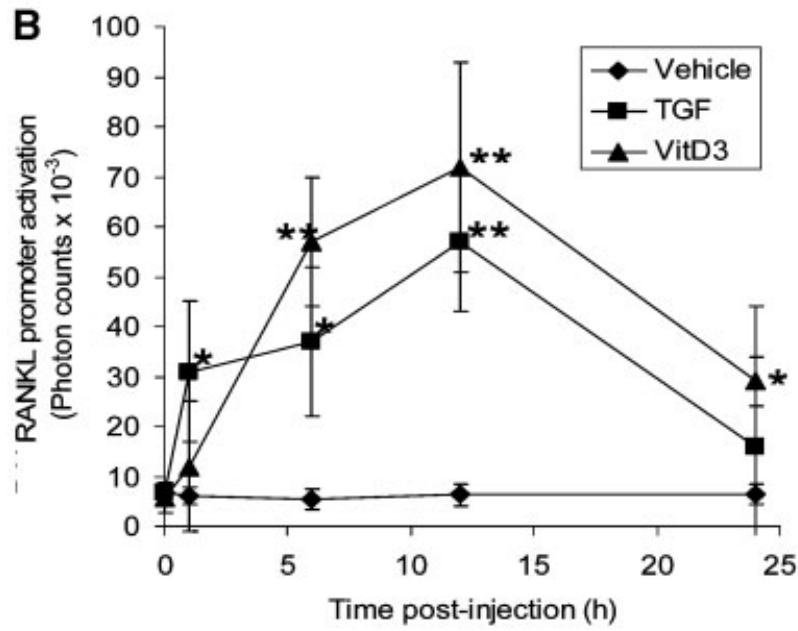

C

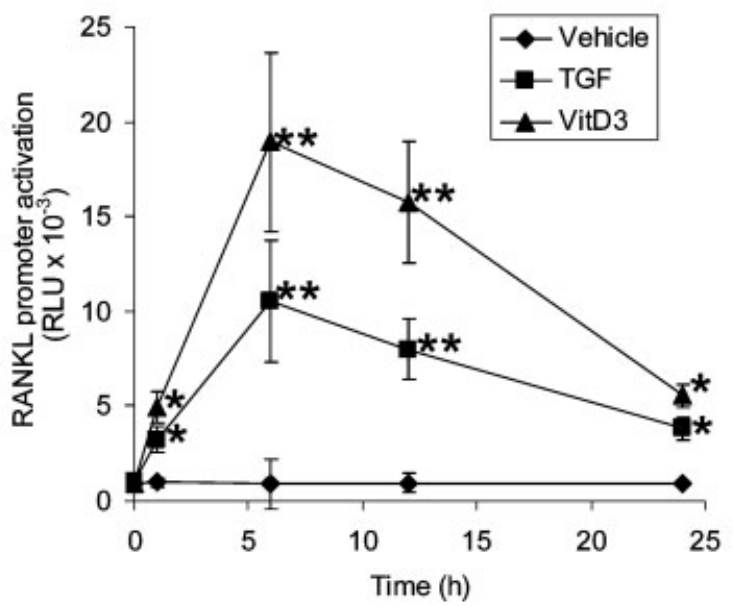

$H \& E$

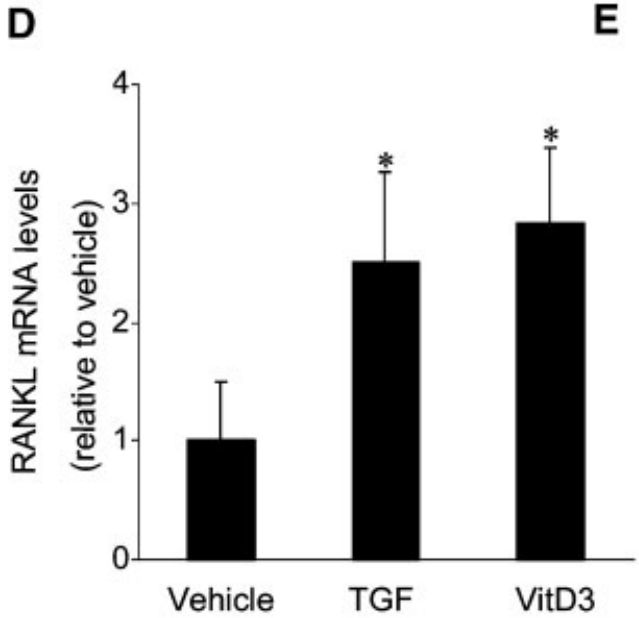

E

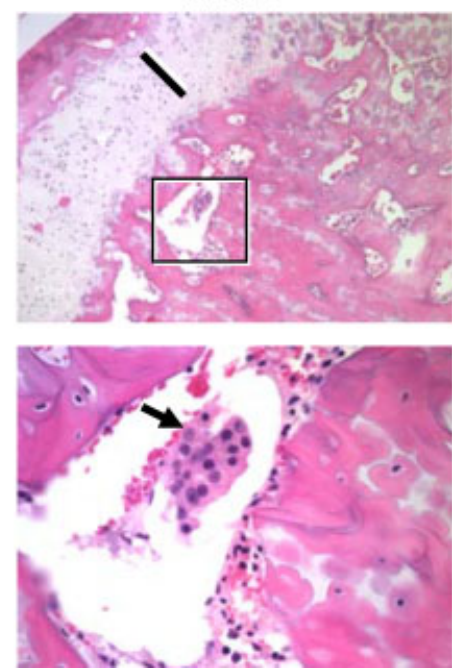

Luciferase

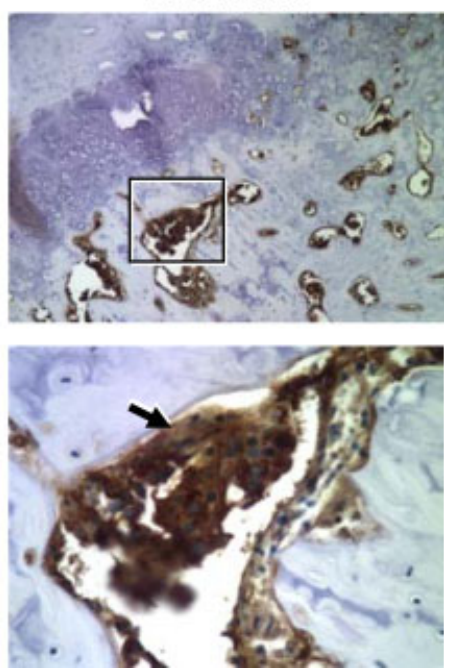

Fig. 4. 
within cancer cells growing in bone in vivo has not been described. The current study was primarily designed to develop a method to identify gene promoter regulation in vivo in intraosseous tumor cells. Accordingly, in the current study, we evaluated the known activating effects of VitD on the RANKL promoter [26] as well as determining if TGF- $\beta$ induced RANKL promoter in vitro, thus setting the groundwork for in vivo evaluation. Our observation that VitD and TGF- $\beta$ induced the RANKL promoter in vivo was supported by the observation that RANKL mRNA levels in the tumors paralleled the BLI results. Finally, the demonstration that lux was present in the CaP cells in the bone confirmed the origin of the lux. Taken together, these results demonstrate that BLI is a sound method for measuring promoter activation in bone in vivo.

Monitoring tumor growth in bone metastases models has been a great challenge due to the inaccessibility of the bone. Typically measurement is made using radiographs. However, radiographs have several drawbacks, including (1) lack of sensitivity as over 50\% of the bone mineral density has to change prior to it being detected as a change on radiographs; (2) they only provide a one dimensional evaluation of the bone and do not allow quantitative determination of total tumor volume; and (3) they are an indirect measure of the tumor, specifically as they only identify the effect of tumor on bone, not the tumor itself. Thus, results from the current study indicate that BLI may have advantages over radiographic imaging of bone tumors and suggest that it is a valuable method for measuring intraosseous tumor growth. The observation that BLI measurement of tumor burden paralleled PSA levels provides a strong level of confidence in the BLI quantification of tumor burden. However, in addition to quantifying tumor burden levels, tumor localization is an advantage that BLI offers over measurement of PSA. In addition to intraosseous growth, we have found that BLI can be used to measure subcutaneous and orthotopic $\mathrm{CaP}$ growth of stably-transfected C4-2B, as well as DU145 and PC-3 CaP cells (data not shown) similar to its ability to be useful for measuring response of brain tumors to chemotherapeutic treatment in rodents [25]. The subcutaneous tumors demonstrated a higher basal level of lux compared to the bone tumors and a similar induction of the promoter with treatment. It is unclear if the higher basal lux levels observed in the subcutaneous tumors was due to microenvironment effects (i.e., bone vs. subcutaneous sites) or due to the fact that the subcutaneous-derived signal did not need to penetrate bone or that there was more tumor mass in the subcutaneous tumors.

Several methods of non-invasive imaging of animal cancer models have been developed (reviewed in Ref. 28). Micro-positron emission tomography (MicroPET) has been used to identify uptake of systemically and intratumorally administered reporter virus in a variety of cancer cells (reviewed in Ref. 29) including $\mathrm{CaP}$ cells xenografts in mice [30]. Micro-PET could identify the tumors; however, significant systemic transgene leakage occurred resulting in significant hepatic expression of reporter. This contrasts with the current study in which lux expression is maintained at the site of tumor cells. Regardless, the MicroPET method offers the potential of being able to track gene therapy in clinical cases. In another study [31], demonstrated the ability to detect adenoviral-mediated lux expression was detected in skeletal muscle of mice using a cooled charged coupled device (CCD) camera. This method demonstrated great sensitivity for detecting lux for a duration of greater than 150 days. Similarly, in the current study, we observed lux activity in tumor cells for an extended period of time (i.e., for 42 days, at which time mice were sacrificed), which

Fig. 4. BLI detects that TGF- $\beta$ activates the RANKL promoter in $C 4-2 B$ cells in bone in vivo. C4-2B CaP cells were stably transfected with a reporter vector of the RANKL promoter driving lux. The transfected C4-2B cells were injected intratibially into SCID mice tumors were allowed to develop over 6 weeks and vehicle (phosphate-buffered saline, PBS), TGF- $\beta$ (I00 ng/mouse), or I,25-dihydroxyvitamin D (VitD3) ( $200 \mathrm{ng} / \mathrm{mouse}$ ) in propylene glycol was then administered intraperitoneally into the mice $(\mathrm{n}=6 /$ group). The mice were then anesthetized at the indicated times pre- or post-injection and BLI was performed. Photon counts were collected over a minute period. A: Representative BLI images of mice treated with eitherTGF- $\beta$ or VitD3. The same mouse is shown over time for each treatment. The scale bar indicates luminescence intensity from high $(\mathrm{H})$ to low $(\mathrm{L})$. B: Luciferin was injected 10 min prior to the desired timepoint for BLI measurement. Luminescence emitted from the mouse was then integrated for I min starting $10 \mathrm{~min}$ after injection of luciferin. Results are reported as mean $\pm S D(n=6 /$ group). $* P<0.05$, **P $<0.01$ compared with pre-treatment (pre-) for that compound. C: Stably transfected C4-2B clones were pooled and plated in 12-well-plates and treated with TGF- $\beta(10 \mathrm{ng} / \mathrm{ml})$ or I,25-dihydroxyvitamin D (VitD3; $10 \mathrm{nM})$ for $24 \mathrm{hr}$. Cells were then collected for measurement of lux on a luminometer. Results are reported as mean $\pm S D$ of two experiments. $* P<0.05$, $* * P<0.01$ compared with pre-treatment (pre-) for that compound. D: A section of the intratibial tumors were mechanically ground and then homogenized to collect total RNA which was then subjected to real-time PCR for RANKL mRNA and GAPDH mRNA. RANKL mRNA levels were normalized to GAPDH mRNA levels. Results are reported as mean $\pm S D$. $* P<0.01$ compared with vehicle. E: Sections of intratibial tumors were decalcified and processed for histology. Sections were stained with hematoxylin and eosin $(\mathrm{H} \& \mathrm{E})$ or subjected to immunohistochemistry for lux. The top sections are $100 \times$ magnification and the bottom sections (indicated by the squares in the top section) are $400 \times$ magnification. The bar represents the cartilage epiphysis. Bone is represented by pink osteoid. Tumor cells are seen surrounded by bone and are indicated by the arrow. In the lux sections, lux is represented by the brown color. [Color figure can be viewed in the online issue, which is available at www.interscience.wiley.com.] 
demonstrates the utility of this method for longitudinal studies.

Cross-talk between tumor and bone occurs has been postulated to play a major role in the development of $\mathrm{CaP}$ bone metastases [1,2]. The basal levels of RANKL promoter activity induced in the C4-2B tumors implanted into bone may have been due to a variety of factors that have been shown to induce RANKL expression including interleukins-1 [32] and -11 [33], parathyroid hormone [34] and TNF [33]. When CaP cells grow in bone, they induce bone resorption, which results in release of many bone ECM factors, including TGF- $\beta$ [22]. TGF- $\beta$ signals through TGF $\beta$-I and TGF $\beta$-II receptors which have been identified in normal as well as in cancerous human and animal prostate cells $[35,36]$. However, expression of TGF- $\beta$ receptors in $\mathrm{CaP}$ is controversial [37], yet several studies have demonstrated that TGF- $\beta$ is functional in CaP cells [38-41]. Data from the current manuscript demonstrate that TGF- $\beta$ activates the RANKL promoter resulting in increased RANKL production, which has been reported to allow the CaP cells to induce osteoclastogenesis and osteoclast activation that results in bone resorption [5]. The resorptive component of $\mathrm{CaP}$ has been shown by several studies to be an important component of the establishment of osteoblastic $\mathrm{CaP}$ bone metastases $[2,6,42]$. Thus, results from the current study suggest that $\mathrm{CaP}$-induce bone resorption, which releases TGF- $\beta$, will further enhance RANKL production and more bone resorption in a vicious cycle. However, due to the overall osteoblastic nature of $\mathrm{CaP}$, there must be regulation of this osteoclastogenic activity. One possible regulator of this activity is OPG, an inhibitor of RANKL, which is produced by $\mathrm{CaP}$ cells $[10,43,44]$ and is elevated in the serum of men with $\mathrm{CaP}[45]$.

In conclusion, we described a method to measure $\mathrm{CaP}$ tumor growth in bone over time and a novel method for determination of promoter activation within formed $\mathrm{CaP}$ tumors in the bone microenvironment in vivo. Using the latter method, we determined that TGF- $\beta$ induces RANKL expression through activation of the RANKL promoter in $\mathrm{CaP}$ in bone. This finding is consistent with the idea the cross-talk between tumor and bone is important in the development of bone metastases [2] and identifies TGF- $\beta$ as a potential target to regulate the establishment of $\mathrm{CaP}$ growth in bone. Additionally, the methodology used to measure promoter activity in vivo should be useful for determining the influence of microenvironment (e.g., bone vs. liver metastatic sites) on gene regulation in cancer cells and can be useful to test the effect on gene promoter modulation of compounds that are metabolized to active forms in vivo, which cannot be tested in vitro. Finally, this methodology has the poten- tial to be useful for evaluating therapies designed to modulate regulation of cancer relevant genes including monitoring both tumor volume and gene regulation.

\section{REFERENCES}

1. Rosol TJ. Pathogenesis of bone metastases: Role of tumor-related proteins. J Bone Miner Res 2000;15(5):844-850.

2. Keller ET, Zhang J, Cooper CR, Smith PC, McCauley LK, Pienta KJ, Taichman RS. Prostate carcinoma skeletal metastases: Cross-talk between tumor and bone. Cancer Metastasis Rev 2001;20(3-4):333-349.

3. Charhon SA, Chapuy MC, Delvin EE, Valentin-Opran A, Edouard CM, Meunier PJ. Histomorphometric analysis of sclerotic bone metastases from prostatic carcinoma special reference to osteomalacia. Cancer 1983;51(5):918-924.

4. Urwin GH, Percival RC, Harris S, Beneton MN, Williams JL, Kanis JA. Generalised increase in bone resorption in carcinoma of the prostate. Br J Urol 1985;57(6):721-723.

5. Zhang J, Dai J, Qi Y, Lin DL, Smith P, Strayhorn C, Mizokami A, $\mathrm{Fu} \mathrm{Z}$, Westman J. Osteoprotegerin inhibits prostate cancerinduced osteoclastogenesis and prevents prostate tumor growth in the bone. J Clin Invest 2001;107(10):1235-1244.

6. Yonou H, Kanomata N, Goya M, Kamijo T, Yokose T, Hasebe T, Nagai K, Hatano T, Ogawa Y, Ochiai A. Osteoprotegerin/ osteoclastogenesis inhibitory factor decreases human prostate cancer burden in human adult bone implanted into nonobese diabetic/severe combined immunodeficient mice. Cancer Res 2003;63(9):2096-2102.

7. Clarke NW, McClure J, George NJ. Disodium pamidronate identifies differential osteoclastic bone resorption in metastatic prostate cancer. Br J Urol 1992;69(1):64-70.

8. Burgess TL, Qian Y, Kaufman S, Ring BD, Van G, Capparelli C, Kelley M, Hsu H, Boyle WJ, Dunstan CR, Hu S, Lacey DL. The ligand for osteoprotegerin (OPGL) directly activates mature osteoclasts. J Cell Biol 1999;145(3):527-538.

9. Kostenuik PJ, Shalhoub V. Osteoprotegerin: A physiological and pharmacological inhibitor of bone resorption. Curr Pharm Des 2001;7(8):613-635.

10. Brown JM, Corey E, Lee ZD, True LD, Yun TJ, Tondravi M, Vessella RL. Osteoprotegerin and rank ligand expression in prostate cancer. Urology 2001;57(4):611-616.

11. Lee Y, Schwarz E, Davies M, Jo M, Gates J, Wu J, Zhang X, Lieberman JR. Differences in the cytokine profiles associated with prostate cancer cell induced osteoblastic and osteolytic lesions in bone. J Orthop Res 2003;21(1):62-72.

12. Kartsogiannis V, Zhou H, Horwood NJ, Thomas RJ, Hards DK, Quinn JM, Niforas P, Ng KW, Martin TJ, Gillespie MT. Localization of RANKL (receptor activator of NF kappa B ligand) mRNA and protein in skeletal and extraskeletal tissues. Bone 1999;25(5):525-534.

13. Weitzmann MN, Cenci S, Rifas L, Haug J, Dipersio J, Pacifici R. T cell activation induces human osteoclast formation via receptor activator of nuclear factor kappaB ligand-dependent and -independent mechanisms. J Bone Miner Res 2001;16(2):328337.

14. Kotake S, Udagawa N, Hakoda M, Mogi M, Yano K, Tsuda E, Takahashi K, Furuya T, Ishiyama S, Kim KJ, Saito S, Nishikawa T, Takahashi N, Togari A, Tomatsu T, Suda T, Kamatani N. Activated human $\mathrm{T}$ cells directly induce osteoclastogenesis from human monocytes: Possible role of T cells in bone destruction in rheumatoid arthritis patients. Arthritis Rheum 2001;44(5): 1003-1012. 
15. Locklin RM, Khosla S, Turner RT, Riggs BL. Mediators of the biphasic responses of bone to intermittent and continuously administered parathyroid hormone. J Cell Biochem 2003;89(1): 180-190.

16. Fu Q, Jilka RL, Manolagas SC, O'Brien CA. Parathyroid hormone stimulates receptor activator of NFkappa B ligand and inhibits osteoprotegerin expression via protein kinase A activation of cAMP-response element-binding protein. J Biol Chem 2002; 277(50):48868-48875.

17. Kitazawa R, Kitazawa S, Maeda S. Promoter structure of mouse RANKL/TRANCE/OPGL/ODF gene. Biochim Biophys Acta 1999;1445(1):134-141.

18. Collin-Osdoby P, Rothe L, Anderson F, Nelson M, Maloney W, Osdoby P. Receptor activator of NF-kappa B and osteoprotegerin expression by human microvascular endothelial cells, regulation by inflammatory cytokines, and role in human osteoclastogenesis. J Biol Chem 2001;276(23):20659-20672.

19. Palmqvist $P$, Persson E, Conaway HH, Lerner UH. IL-6, leukemia inhibitory factor, and oncostatin $\mathrm{M}$ stimulate bone resorption and regulate the expression of receptor activator of NF-kappa B ligand, osteoprotegerin, and receptor activator of NF-kappa B in mouse calvariae. J Immunol 2002;169(6):3353-3362.

20. Koshihara Y, Hoshi K, Okawara R, Ishibashi H, Yamamoto S. Vitamin K. Stimulates osteoblastogenesis and inhibits osteoclastogenesis in human bone marrow cell culture. J Endocrinol 2003;176(3):339-348.

21. Yan T, Riggs BL, Boyle WJ, Khosla S. Regulation of osteoclastogenesis and RANK expression by TGF-beta1. J Cell Biochem 2001;83(2):320-325.

22. Guise TA. Molecular mechanisms of osteolytic bone metastases. Cancer 2000;88(Suppl 12):2892-2898.

23. Wu TT, Sikes RA, Cui Q, Thalmann GN, Kao C, Murphy CF, Yang H, Zhau HE, Balian G, Chung LW. Establishing human prostate cancer cell xenografts in bone: Induction of osteoblastic reaction by prostate-specific antigen-producing tumors in athymic and SCID/bg mice using LNCaP and lineage-derived metastatic sublines. Int J Cancer 1998;77(6):887-894.

24. Anderson DM, Maraskovsky E, Billingsley WL, Dougall WC, Tometsko ME, Roux ER, Teepe MC, DuBose RF, Cosman D, Galibert L. A homologue of the TNF receptor and its ligand enhance T-cell growth and dendritic-cell function. Nature 1997; 390(6656):175-179.

25. Rehemtulla A, Stegman LD, Cardozo SJ, Gupta S, Hall DE, Contag $\mathrm{CH}$, Ross BD. Rapid and quantitative assessment of cancer treatment response using in vivo bioluminescence imaging. Neoplasia 2000;2(6):491-495.

26. Kitazawa R, Kitazawa S. Vitamin D(3) augments osteoclastogenesis via vitamin D-responsive element of mouse RANKL gene promoter. Biochem Biophys Res Commun 2002;290(2):650-655.

27. Zhang W, Feng JQ, Harris SE, Contag PR, Stevenson DK, Contag $\mathrm{CH}$. Rapid in vivo functional analysis of transgenes in mice using whole body imaging of luciferase expression. Transgenic Res 2001;10(5):423-434.

28. Lewis JS, Achilefu S, Garbow JR, Laforest R, Welch MJ. Small animal imaging: Current technology and perspectives for oncological imaging. Eur J Cancer 2002;38(16):2173-2188.

29. GambhirSS. Molecular imaging of cancer with positron emission tomography. Nat Rev Cancer 2002;2(9):683-693.

30. Pantuck AJ, Berger F, Zisman A, Nguyen D, Tso CL, Matherly J, Gambhir SS, Belldegrun AS. CL1-SR39: A noninvasive molecular imaging model of prostate cancer suicide gene therapy using positron emission tomography. J Urol 2002;168(3):1193-1198.
31. Wu JC, Sundaresan G, Iyer M, Gambhir SS. Noninvasive optical imaging of firefly luciferase reporter gene expression in skeletal muscles of living mice. Mol Ther 2001;4(4):297-306.

32. Weitzmann MN, Cenci S, Rifas L, Brown C, Pacifici R. Interleukin-7 stimulates osteoclast formation by up-regulating the T-cell production of soluble osteoclastogenic cytokines. Blood 2000;96(5):1873-1878.

33. Nakashima T, Kobayashi Y, YamasakiS, Kawakami A, Eguchi K, Sasaki H, Sakai H. Protein expression and functional difference of membrane-bound and soluble receptor activator of NFkappaB ligand: Modulation of the expression by osteotropic factors and cytokines. Biochem Biophys Res Commun 2000; 275(3):768-775.

34. Ma YL, Cain RL, Halladay DL, Yang X, Zeng Q, Miles RR, Chandrasekhar S, Martin TJ, Onyia JE. Catabolic effects of continuous human PTH (1-38) in vivo is associated with sustained stimulation of RANKL and inhibition of osteoprotegerin and gene-associated bone formation. Endocrinology 2001;142(9): 4047-4054.

35. Wikstrom P, Lindh G, Bergh A, Damber JE. Alterations of transforming growth factor beta1 (TGF-beta1) and TGFbeta receptor expressions with progression in Dunning rat prostatic adenocarcinoma sublines. Urol Res 1999;27(3): 185-193.

36. Wong YC, Xie W, Tsao SW. Structural changes and alteration in expression of TGF-beta1 and its receptors in prostatic intraepithelial neoplasia (PIN) in the ventral prostate of noble rats. Prostate 2000;45(4):289-298.

37. Wikstrom P, Damber J, Bergh A. Role of transforming growth factor-beta1 in prostate cancer. Microsc Res Tech 2001;52(4): 411-419.

38. Steiner MS, Wand GS, Barrack ER. Effects of transforming growth factor beta 1 on the adenylyl cyclase-cAMP pathway in prostate cancer. Growth Factors 1994;11(4):283-290.

39. Chipuk JE, Cornelius SC, Pultz NJ, Jorgensen JS, Bonham MJ, Kim SJ, Danielpour D. The androgen receptor represses transforming growth factor-beta signaling through interaction with Smad3. J Biol Chem 2002;277(2):1240-1248.

40. Kang HY, Lin HK, Hu YC, Yeh S, Huang KE, Chang C. From transforming growth factor-beta signaling to androgen action: Identification of Smad3 as an androgen receptor coregulator in prostate cancer cells. Proc Natl Acad Sci USA 2001;98(6): 3018-3023.

41. Kim IY, Zelner DJ, Lee C. The conventional transforming growth factor-beta (TGF-beta) receptor type I is not required for TGF-beta 1 signaling in a human prostate cancer cell line, LNCaP. Exp Cell Res 1998;241:151-160.

42. Corey E, Brown LG, Quinn JE, Poot M, Roudier MP, Higano CS, Vessella RL. Zoledronic acid exhibits inhibitory effects on osteoblastic and osteolytic metastases of prostate cancer. Clin Cancer Res 2003;9(1):295-306.

43. Penno H, Silfversward CJ, Frost A, Brandstrom H, Nilsson O, Ljunggren $\mathrm{O}$. Osteoprotegerin secretion from prostate cancer is stimulated by cytokines, in vitro. Biochem Biophys Res Commun 2002;293(1):451-455.

44. Holen I, Croucher PI, Hamdy FC, Eaton CL. Osteoprotegerin (OPG) is a survival factor for human prostate cancer cells. Cancer Res 2002;62(6):1619-1623.

45. Brown JM, Vessella RL, Kostenuik PJ, Dunstan CR, Lange PH, Corey E. Serum osteoprotegerin levels are increased in patients with advanced prostate cancer. Clin Cancer Res 2001;7(10): 2977-2983. 